This is an electronic reprint of the original article. This reprint may differ from the original in pagination and typographic detail.

Author(s): Huang, Jiehua; Aaltio, liris

Title: Guanxi and social capital: Networking among women managers in China and Finland

Year: $\quad 2014$

Version:

Please cite the original version:

Huang, J., \& Aaltio, I. (2014). Guanxi and social capital: Networking among women managers in China and Finland. International Journal of Intercultural Relations, 39, 22-39. https://doi.org/10.1016/j.ijintrel.2013.09.002

All material supplied via JYX is protected by copyright and other intellectual property rights, and duplication or sale of all or part of any of the repository collections is not permitted, except that material may be duplicated by you for your research use or educational purposes in electronic or print form. You must obtain permission for any other use. Electronic or print copies may not be offered, whether for sale or otherwise to anyone who is not an authorised user. 


\title{
Guanxi and Social Capital: Networking among Women Managers in China and Finland
}

\author{
Jiehua Huang \\ Department of Psychology, School of Education, Guangzhou University, China \\ Iiris Aaltio \\ (corresponding author) \\ School of Business and Economics, University of Jyväskylä, Finland
}




\begin{abstract}
Considering that women are still under-represented in management, researchers have claimed that networking is an important career management tool for women. This study aims to empirically explore how women managers benefit from social networks in the information technology (IT) field in China and Finland. Guanxi, an Eastern term for social networking, has seldom been studied in terms of gender and career, especially within cross-cultural research. Social capital is a Western term for social networks. Using questionnaires, in-depth interviews and interpretive analysis, we compare the composition and structure of social networks used by women managers within the information technology sector in the two countries. The results show: (1) that in both contexts, there is an effect of femaleto-male dyads, which are mainly within power- and work-related networks (e.g. most ties of 'influence’ are with older men) while female-to-female dyads are mostly 'social', (2) China has relatively small networks while Finland has networks differentiated on the basis of function, and (3) there are differences in the structure and participant strategies in networks and networking in the two contexts. Both guanxi and social capital include elements of who know you" and "who knows you" that are important for career success. We suggest that a strategic and cross-gender, cross-company approach to networking would assist women in career advancement. Moreover, deeper research should be undertaken into the nature of the social ties that carry networks because these are based on countryspecific traditions even when they appear superficially similar. Implications for international human resource management are also discussed.
\end{abstract}

Key words : guanxi, social capital, networks, women managers, China, Finland 


\section{Guanxi and Social Capital: Networking among Women Managers in China and Finland}

Since globalization is continuously redefining relationships between business organizations throughout the world, the role of culture - national and organizational - has been the topic of numerous recent studies focusing on various aspects of human behavior (Adya, 2008; Fang \& Faure, 2011; Faure \& Fang, 2008; Tams \& Arthur, 2007; Weisinger \& Trauth, 2003). At the same time, "strategies that call for the simultaneous deployment of diametrically opposed principles" (Fang, 2011, 25), such as glocalization, which combines both global and local trends (ibid., 34, Bartlett \& Ghoshal, 1989), have emerged. National cultures are dynamic and changing in addition to being stable and strong and navigating across worlds has increased. Multinational companies as well as the internet (Takahashi et al., 2008) and distance transcending technology are generating cultural interaction. Widespread immigration increases the cultural mix (DelCampo et al., 2011) and makes aspects of discrimination worth studying. Biculturalism, where two originally distinct cultures are in some form of co-existence, extends our understanding of culture and nationality. It can represent comfort and proficiency with both one's heritage culture and the culture of the country or region in which one has settled (Schwarz \& Unger, 2010). In spite of the cultural dynamism mentioned above, cultural traditions still have considerable impact within national boundaries. As found by Pan et al. (2011), in their study of Chinese cultural traditions using a model of cultural traditions among business employees, traditions still provide a unique model for Chinese culture and provide a deep inner understanding.

Gender, including the cultural aspects of the behavior of women and men, crosses national boundaries, as found in studies involving international comparisons (Davidson \& Burke (2004), as well as carrying elements of national cultural heritage. We ask, what is the meaning of national culture to women's managerial careers within the framework of social relations and networks. Our approach is feminist, because we see that independent of cultural boundaries women stay at the margins of management, and we suppose that human relations and networks partly explain this.

The under-representation of women in non-traditional occupations (e.g., management and the information technology (IT) field) has been widely documented in Western literature, and has been related to culture, especially organizational culture (Ahuja, 2002; Burke \& Nelson, 2002; Kaplan \& Niederman, 2006; Trauth, 2002). In addition to the well-known concept of the glass ceiling and perceived masculinity in the field, researchers have pointed out that inadequate social networks, especially informal ones, have been a hurdle to career success for women (Kanter 1977; Kaplan \& Niederman, 2006; Powell, 2000). According to social capital theorists, individuals are embedded in networks of social relationships with other economic actors, and social networks represent a source of 
competitive advantage (e.g., Nahapiet \& Ghoshal, 1998; Putnam, 1995). By adopting a relational approach, we can deepen our understanding of social networks as a source of sustained competitive advantage in different contexts Eastern and Western (Ordonez de Pablos, 2005) - which connect networking and social spheres of work to culture from a dynamic and situational perspective (Leung et al., 2005; Weisinger \& Trauth, 2003).

Usually, good performance and close social networks are seen as connected both in Western literature (Fukuyama, 1995) and in China (Luo et al., 2011). It is, however, not self-evident what is meant by successful networks (Luo et al., 2011) or successful careers (Gunz et al., 2005). Women may both benefit and suffer from social relations and networks in their careers. As found by Aaltio and Huang (2007), rich social networks for Chinese career-orientated women may also damage their informal social networks and cause a dual-effect, both positive and negative. This finding also indicates the need to be culturally sensitive in studying questions of career and gender. To explore the cross-cultural nature of women's managerial careers, we conducted a cross-cultural study of networking among women managers in the IT field in China and Finland. In particular, we focused on the composition and structure of guanxi (an Eastern term for social networks) and social capital (a Western term for social networks) and how they might relate to the careers of women managers. The study uses both qualitative and quantitative methods and is therefore based on a mixed method approach.

This study is situated within the following theoretical context. First, studies on guanxi dominate Chinese management literature (Chou \& Ng, 2004; Tsui \& Farh, 1997; Xiao \& Tsui, 2007; etc.); however, guanxi has seldom been studied in terms of gender and career perspectives, especially within a cross-cultural context. Leung (2000) points out that gender issues and Chinese cultural traditions, such as guanxi, are major factors influencing career development and managerial growth in China. Second, according to Ibarra (1993), network and management theories should be integrated when discussing how managers build and utilize informal personal relationships to achieve goals. Third, people act through networking, and their economic action is embedded in their ongoing network of relationships (Granovetter, 1992); therefore, social network analysis can reveal important elements of the special way women managers build their careers. Fourth, recent advances in theory building in cross-cultural management and Chinese business studies (Fang, 2010; Faure \& Fang, 2008) hold to a dynamic vision of Chinese culture and communication - a Yin Yang perspective to understanding culture (Fang, 2012). Although studies of guanxi and social capital originate from different cultures, both were explored within sociology first and spilled over into the study of management later. Their similar background makes it possible to compare them, especially within the newly developed field of IT in today's globalizing context. Accordingly, people in a high-tech industry like IT have been 
experiencing transformational changes and high mobility, which make them the subject of social network studies (Ahuja, 2002; Adya, 2008; Xiao \& Tsui, 2007).

Using in-depth interviews, questionnaires and social network analysis to study how women managers network in a cross-cultural context, this study contributes to the literature on gender and work, and social networks. We start with a literature review and theoretical background. We then present the empirical study on women managers' networking in China and Finland. Next, we interpret the results and compare how women managers network in both contexts. The final section presents conclusions with suggestions for future research.

\section{Literature Review and Theoretical Background}

\section{A dynamic perspective to understanding culture}

Scholars have different views on culture depending on the degree to which it is believed to be fixed and immutable or variable and emergent. In the field of international cross-cultural management there are two paradigms on culture: the static and the dynamic, with the former dominating the field to date (Fang, 2012). The chief representative of the static paradigm is Hofstede, who defines culture as "the collective programming of the mind" and emphasizes cultural differences across nations (Hofstede, 1980, p. 25). However, in the age of globalization and the internet, Hofstede's cultural paradigm has been criticized for being static and bipolarized (Fang, 2012). As the workplace, marketplace and cyberspace become increasingly borderless and wireless, cultural learning takes place not just longitudinally within one's own cultural group but inter-dimensionally from different nations, cultures and peoples (Fang, 2012). There is a growing awareness that studying cultural dynamics, particularly at the national level, is imperative (Leung et al., 2005).

The dynamic concept of culture can be dated back to the work of Smircich (1983), who proposed that culture is both produced and reproduced through the negotiation and sharing of symbols and meanings. This view of culture highlights the limits of managerial power to manipulate cultural change, because it is not something wholly within the control of managers. Within management literature this approach is known as gender and organizational analysis, which attempts to integrate analyses of organizational structures with explorations of organizational cultures (Acker, 1990; Calas \& Smircich, 1992; Fenstermaker \& West, 2002). Brannen and Salk (2000) hypothesized that as people of different cultures work together in an organizational context a new 'negotiated culture' emerges. Further, some proponents of this dynamic paradigm advocate studying the 'cultural friction' that arises from the actual encounter between cultural systems (Shenkar et al., 2008). Mary Jo Hatch (1993) has modified Schein's model of culture to make a dynamic model, seeing that the main idea of culture is to transform but with a 
certain structure. In her model, values, artifacts, symbols and assumptions all play a role and have an impact on each other in a circular way.

Recent advances in theory building in cross-cultural management and Chinese business studies hold to a dynamic vision of Chinese culture and communication - a Yin Yang perspective to understanding culture (Fang, 2010; Fang, 2012; Faure \& Fang, 2008).

In this study, culture is viewed in generic terms, but interpreted mostly in the context of national culture. It also has dynamic characteristics in order to adapt to political and economic changes. For an individual in a specific national culture, his/her behavior and values are affected by the national culture, organizational culture (if a member of an organization), group culture (if a member of a group) and global culture. The influence of the different levels of culture depends on the context and the individual.

Elements of culture often manifest themselves in complex ways through individual beliefs, national value systems and artifacts that symbolize these beliefs and values (Schein, 1985). In turn, these cultural elements impact societal and organizational structures. In the cultural clusters classified according to Hofstede's (2001) value dimensions, China's country index score is significantly different to Finland's, especially for the individualism/collectivism dimension (China scores 20, making it firmly collectivist, while Finland scores 63 and is individualist), the masculinity/femininity dimension (China scores 66 and is more masculine, while Finland scores 26 and is more feminine) and the power distance dimension (China scores 80, while Finland scores 30). Although Hofstede's cultural consequences have been criticized for the absence of a woman's voice (Moulettes, 2007), there is an obvious difference between China and Finland in terms of traditional culture, social system, economic structure and IT industry (Aaltio \& Huang, 2007; Aaltio \& Heilmann, 2006; Cooke, 2004; Hofstede, 2001; Kolbe, 2005). Moreover, the Global Gender Gap Report 2008 (Hausmann, Tyson \& Zahidi, 2008) shows that China's global gender gap index was 0.6878 (rank 57), while Finland's was 0.8195 (rank 2), indicating Finnish women enjoy much more gender equality than their Chinese counterparts. However, both countries have experienced a profound recent economic transformation: China from a planned economy to a market economy and Finland from a natural-resource-based economy to a competitive and knowledge intensive one, although the degree of transformation may differ.

Communication is usually seen to be at the centre of culture, even in the sense that communication is culture (Hall, 1959). Differing communication rules in the West and East also make networks different. This study emphasizes communication, but also the meaning of stable social relations and networks for one's work and social welfare, especially for making a career in the sense of developing one's self.

\section{Social capital: The Western approach to social networks}


The concept of social capital has become increasingly popular in a wide range of social science disciplines (Coleman, 1988). Social researchers have offered a number of definitions of social capital. Among them, Putnam (1995, p. 67) sees social capital as "features of social organization such as networks, norms, and social trust that facilitates coordination and cooperation for mutual benefit", while Nahapiet and Ghoshal (1998, p. 243) define social capital as "the sum of the actual and potential resources embedded within, available through, and derived from the network of relationships possessed by an individual or social unit”. There are three dimensions of social capital (Nahapiet \& Ghoshal, 1998): the structural dimension refers to the overall pattern of connections between actors - that is, who you reach and how you reach them (Burt, 1992); the relational dimension refers to those assets created and leveraged through relationships; and the cognitive refers to those resources providing shared representations, interpretations and systems of meaning among parties. These three dimensions are highly interrelated. The structural dimension represents the opportunity to benefit from other actors' resources and to act together, thereby representing one source of social capital (Adler \& Kwon, 2002). The relational dimension, on the other hand, represents relation-based motivations for explaining such behaviour: such motivations facilitate the materialization of the benefits of social capital - norms and trust being its sources (Adler \& Kwon, 2002; Putnam, 1993). Finally, the cognitive dimension refers to the ability of the collective to become embedded in such exchanges and the resulting content. Perspectives on social capital are diverse but researchers agree that social capital is a metaphor for advantage, meaning that people or groups who succeed are somehow better connected and this becomes an asset in its own right, which can create a competitive advantage in pursuing their ends (Burt, 2001).

Recently, leading social capital theorists have formalized social capital by using a structural hole theory, which describes how certain network structures offer a competitive advantage by providing access to more opportunities, and the ability to act on those opportunities (see Burt, 1992). The presence of structural holes provides access to diverse sets of information, control of the flow of information between disjoined parties, and the determination of the form of projects that bring together disconnected others. Structural holes are the setting for strategies.

Overall, to achieve networks rich in informational benefits, it is necessary to build large networks with non-redundant contacts. Literature and empirical evidence identify three major benefits of social capital: (1) it smoothes access to broader sources of information, (2) it provides control and influence, and (3) it provides solidarity benefits of closure and trust (Leana \& Van Buren, 1999). From this perspective, social capital should benefit women's careers in non-traditional fields. The larger the network and the greater the number of non-redundant 
contacts and weak ties, the more opportunities women managers should have to benefit their career development.

In a recent study it was found that impression management is seen as necessary by women who want to progress in their careers (Kumra \& Vinnicompe, 2010). However, this can be pursued in a defensive sense and seeing that women need to actively work to dispel the negative stereotypes attached to them because of their gender. Organizational culture has an impact on career advancement and because the organisations are often masculine by nature, women have to conform to masculine cultures they were not active in creating. This requires additional energy and adaptation skills. Impression management might also be contextrelated and its use in Chinese communication might differ from Western use.

\section{Guanxi: An Eastern approach to social networks}

The concept most closely related to social capital in Chinese culture is guanxi, which points to the importance of trust, obligation, and reciprocity in Chinese social interactions (Xiao \& Tsui, 2007). Generally, guanxi refers to relationships between individuals or social connections based on mutual interest and benefit (Bian, 1994; Gold et al., 2002; Yang, 1994). It is understood, that in Chinese culture, to establish the right guanxi and to be included in the in-group is necessary for a successful career and business survival. In this paper, guanxi is defined as a network of ties and its basis is in the relationship between two individuals.

Guanxi begins with a guanxi base, which is defined as "a base in which two or more persons have a commonality of shared identification" (Jacobs, 1979, p. 243). Chen and Chen (2004) have identified three types of guanxi base. The first guanxi base consists of common social identities (Jacobs, 1982). The most frequently claimed common social identities are birthplace (lao xiang), educational institution (tongxue or xiaoyou in Chinese, alumnus in English), and workplace (coworker). This type of guanxi base is different from those salient social identities studied in the West (e.g., race, gender, age, and educational level) (Tsui \& Farh, 1997). Chinese social identities are anchored in specific social institutions with clear social or even physical boundaries (such as a village, school or organization) while the Western identities are anchored in demographic criteria that can cut across institutional boundaries (Chen \& Chen, 2004b). The second type of guanxi base is a common third party, who is generally a mutual friend of both individuals. Through a third party, two individuals can claim to have guanxi for the purpose of obtaining help, resolving problems or simply getting connected. The third type of base is called anticipatory base. Because of the increased marketization of the Chinese economy and the mobility of contemporary Chinese society, individuals can still initiate a guanxi by creating potential future bases through expressing an intention or even a promise to engage in future exchanges, collaborations or joint ventures even though a shared common social identification 
does not exist. These guanxi intentions therefore become guanxi bases for further interactions.

Guanxi is characteristic of traditional Chinese culture. The core of Chinese values involves differentiated attitudes toward parents, children, siblings, kinsmen, and friends; that is, "no tie, no obligation and no rights" (Lee \& Dawes, 2005, p. 29). Guanxi comprises particularistic ties in which instrumental and expressivemoral elements intertwine (Tsui \& Farh, 1997). The value and importance of a tie rests in the type of resources it may provide and the extent to which such resources fulfill individual objectives. Accordingly, guanxi consists of power ties (i.e., the ego's supervisor, who through his or her position of authority may determine whether or not the ego receives a promotion), workflow ties (e.g., the ego's colleague who works as a team member with the ego), strategic information ties (referred to links on whom the ego relies for information, guidance, and coaching), and social support ties (e.g., a friend or family member of the ego offers constant encouragement) (Ibarra, 1993).

With the emergence of a rational-legal system to govern and guide business transactions in China, scholars posit that guanxi practices (using guanxi to get things done) should have declined, although studies indicate that the importance of guanxi relations has remained (Luo, 2005; Tsui, 1997). Globalization, foreign direct investment and the internet are exposing China, for the first time in its history, to unprecedented global knowledge transfer, information sharing, and cultural learning. These changes have had a great impact on Chinese values, with the values of western concepts of management and lifestyle impacting the Chinese mindset. Faure and Fang (2008) have listed eight pairs of contradictory value orientations reflecting the dynamics of current Chinese culture: 1) guanxi vs. professionalism; 2) importance of face vs. self-expression and directness; 3) thrift vs. materialism and ostentatious consumption; 4) family and group orientation vs. individuation; 5) aversion to law vs. respect for legal practices; 6) respect for etiquette, age and hierarchy vs. respect for simplicity, creativity and competence; 7) long-term vs. short-term orientation; and 8) traditional creeds vs. modern approaches (see also Fang \& Faure, 2011). The eight pairs of values represent the interaction of traditional Chinese culture (the first in the pair) and modern western values (the second in the pair).

Mainland China and overseas China differed in the study by Luo et al. (2011). Business ties remained a valuable strategic tool in Mainland China. Both government and business ties were seen as important in strategic progress and maintaining competitive advantage, but overall the importance of government ties was declining because of changes in the institutional environment in China.

Guanxi has also been criticized because of ethical problems (Chen \& Chen, 2009). There are negative effects of the close social relations that are peculiar to it, because these close personal connections and their negative externalities spread to 
the organizations. At the individual level, guanxi benefits the firm only if the individual wants it to. When leaving the firm the benefit is taken with the individual and may be wasted for the individual and the firm. Dunfee \&Warren (2001) state that there are potentially problematic aspects of guanxi like bribery and corruption. The consequences of this in business are manifold. It may bring benefits to individuals and organizations but the benefits are obtained at the expense of other individuals or firms. Close male guanxi may make women outsiders without access to core social networks in the company, so women may end up being unutilised resources. Chen, Chen and Xin (2004) found the negative effect of guanxi practices on trust in the management, but favouring a college schoolmate did not raise so much negative emotions compared to a close friend.

\section{The social networks perspective and managerial careers for women}

The central focus of the social networks perspective is the composition and structure of social interactions and how these compositions and structures enhance or constrain access to valued resources (Bu \& Roy, 2005; Burt, 1997; Ibarra, 1997). In this view, networking is seen as increased exposure to other people both within and outside the organization, which may enhance understanding of organizational practices and provide valuable information and so on (Lankau \& Scandura, 2002). Networking is the building and nurturing of personal and professional relationships to create a system of information, contact and support; all together, this is thought to be crucial for the career and personal success of women (Whiting \& De Janasz, 2004). In Björkman and Kock’s (1995) study about Western and Chinese managers, it is recognized that the first direct benefit of both guanxi and social capital is information that can be used for one's benefit. At the individual level, they perceive that having a network of social ties clearly influences their career success in terms of earlier promotions and compensation.

Characteristics of social networks are important for women wanting to advance to higher hierarchical levels. Organizational researchers have argued that informal networks are more important than formal ones (e.g., Burt, 1992). Besides, informal networks also provide friendship and social support (Ibarra, 1993, 1997). However, women in organizational settings are often reported to experience limited or indeed no access to informal networks (Kanter, 1977; O’Leary \& Ickovics, 1992). Studies have pointed specifically to the exclusion of women from networks, especially when these exist above the glass ceiling (e.g., DaviesNetzley, 1998; Lyness \& Thompson, 2000). These studies emphasize the importance of examining women's networking relationships, because if women develop less effective network relationships, they may miss essential ingredients important for career success (Burke et al., 1995).

According to Wellman (2001, p. 231), "at the network level of analysis, researchers of social networks look at the composition of the networks (e.g., network size, network heterogeneity, mean frequency of contact) and the structure 
of these networks (e.g., density of links among alters).” The network analysis literature supports the assertion that the size and heterogeneity of a network (its range) affect its members' access to resources (Burt, 1992; Ibarra, 1993, 1997). Heterogeneous networks - having a variety of network members with different characteristics - and networks with more socioeconomic resources can better mobilize supportive network capital (Lin, 2001). Structuralists have also argued that the sex composition of groups and organizations constrains the extent of network contact between men and women co-workers (Ibarra, 1997). Women's exclusion from the formal network structure in an organization has negatively affected their advancement within the corporate environment and participation on corporate boards. As women are also excluded from informal networks, they consequently lack access to real time information through the grapevine (Burke et al., 1995). Therefore, the composition and structure of networks are crucial to understanding women's networking.

The above studies and analysis have provided important logical support and inspiration for the current study, arguing that the guanxi and social capital views of social networks revolve around similar activities, although their manifestation and importance may differ.

\section{Methods and Data}

Intercultural researchers are deemed to have certain challenges due to cultural, linguistic, business practice and communication differences between research participants, survey respondents and interviewees. To make cross-cultural comparisons, researchers use a combined quantitative-qualitative approach (cf. Polsa, 2002; Schaffer \& Riordan, 2003). In this study, a mixed method quantitative (questionnaire) and qualitative (in-depth interview) - was chosen in order to explore networking among women managers. The quantitative mode of inquiry is based on the assumption that social reality has an objective ontological structure and that individuals are agents that respond to this objective environment (Morgan \& Smircich, 1980). Qualitative approaches focus on studying phenomena that occur in natural settings and emphasize the subjective nature of reality. They provide detailed descriptions of socially constructed realities and the meaning assigned to particular experiences (Marshall \& Rossman, 1999). The ability to seek an in-depth understanding is the strength of this method, as the researcher "builds a complex, holistic picture, analyzes words, reports detailed views of informants" (Creswell, 1998, p. 15). Therefore, the mixed method cannot only provide a high level of measurement precision and statistical power, but also a greater depth of information about the nature of communication processes in a particular research setting. Both the interviews and the questionnaire focused on obtaining information about networking, its style and content as well as a basic understanding about what is meant by networking. 


\section{Research questions}

The main research question in this study is: How does the composition and structure of social networks affect the experiences of women managers? The empirical analysis focuses on three interrelated questions and explores the gender aspects of organizations and management. The research includes the following sub-questions:

RQ1. How do women managers in China and Finland conceptualize and experience social networks?

RQ2. What comprises the social networks of women managers and how do these social networks relate to gender, power, work and the individual?

RQ3. How does family social support contribute to the career of women managers in China and Finland?

\section{Respondents}

To explore the effect of social networks on women managers' career trajectories, we used the 'snowball' method (Singleton \& Straits, 1999) for sampling the respondents in order to obtain access to the IT industry and in order to obtain motivated respondents. Data was collected from 21 and 15 women IT managers respectively in China and Finland. In this study, a manager is defined as a person who plans, organizes, motivates, directs, and controls in the middle level of an organization, with at least one subordinate. The first author, who is Chinese, conducted the fieldwork (interviews and questionnaire) both in China (during March to June 2005) and in Finland (during September to December 2005).

A senior editor of the IT column for Yangcheng Evening Post (Yangchengwanbao), a Chinese newspaper in southern China, introduced the first author to six possible Chinese participants, who were women managers from IT companies in the region. Then, each participant was asked to introduce one or two female counterparts in the field. In China, it is difficult to obtain access to academic research participants without guanxi. As Weiss (1994) notes, in Asia business is based on relationships and questionnaires are often viewed with suspicion. In Finland, some participants were introduced to the study by the authors' Finnish colleagues (and these colleagues' colleagues), some were introduced by the participants and some by their HR departments, which the first author had contacted by email. It is interesting to note that two Finnish participants were contacted directly because their names appeared in a Finnish newspaper. This indicates that Finnish people are more likely to participate voluntarily in academic research than Chinese people. The "snowball" method worked well not only in China, but also in Finland.

The demographic characteristics of the participants are presented in

Table 1. The hierarchical positions of the Chinese participants include one CEO, 
five who are one level from being CEO, and fifteen department managers. The Finnish participants include three CEOs, four who are one level from being CEO, and eight department managers.

\section{[Insert Table 1 about here]}

\section{Interviews}

To maximize convenience for the participants, the face-to-face interviews were conducted at various sites, either in the interviewees' offices, or at sites (meeting room, coffee bar etc.) chosen by the interviewees in Finland and in China. Each interview lasted about 45-60 minutes. The interviews were based on semi-structured questions and started by looking at the work history and life story of the participant, then focusing on the three research questions about how social network composition and structure affect the experiences of women managers. All the participants were asked about their social networks when they sought advice, information, influence, help in a crisis and socialization outside work. The language used in the interviews was Chinese (or Mandarin) in China. In fact, most of the interviewees could speak at least a little English; they often even used some single English words when they were telling their stories. The language used in the interviews in Finland was English. All the Finnish participants spoke English very well, though their native language was Finnish. The interviews were recorded. This gave the researcher the opportunity to observe the facial expressions and body language of the interviewee, which helped to interpret the factors that emerged in the statistical analysis. Each interview recording was transcribed in detail after the event. For the fieldwork in China, two female English major students respectively translated the transcription of the Chinese participants' interviews from Chinese to English, and a third person, a male English language teacher (who is Chinese), revised both translations and developed the final version of the translation. Both the English major students and the English teacher were unaware of the purpose of the research. The interview records in Finland were transcribed using a transcription service company in Finland.

\section{Questionnaire}

After the interview, the participants were asked to complete a questionnaire. Concerning the schedule of the participants, most of the questionnaires were completed and sent to the first author by email within two weeks of the interviews. The questionnaire was designed to ask the participants to provide information on their associates in five network contexts. The name-generator approach (Marsden, 1987) can be employed to ascertain the composition of social networks. This approach focuses on a core discussion network. We adopted a simplified nameeliciting method that allowed the associates to remain anonymous. This works well to help ease participant suspicion. As previous results indicate that 95 percent of people report fewer than five individuals in their (core discussion) networks 
(Marsden, 1987), the participants were asked to "identify up to five people with whom you have: (1) sought advice on a decision you had to make, (2) sought information on what is going on in the organization, (3) sought help when you want to influence the outcome of an important decision at work, (4) sought help in times of (personal) crisis, and (5) socialized outside work" (cf. Chow \& Ng, 2004). These five questions sum up the network content for these women IT managers concerning their work and life.

For the five types of network content one can seek as favors, the first three (advice, information, and influence) are more work-related, while the last two (crisis and social) are more life-related. However, work and life are not always separated. Sometimes they overlap. From a cost perspective, both advice and information content can be considered to have similar value. However, the 'influence' content requires the favour granter to do more than converse with the recipient, and the favour granter must show his/her power, professional expertise or rich experience to have influence. Therefore, the 'influence' content belongs to power-related ties. Similarly, help during a 'crisis' situation suggests a level of deep involvement and trust. From the perspective of work-life balance, to 'socialize' is also important in today's information society. One cannot live without the social component.

Concerning the design of the questionnaire, three Finnish participants commented that completing the questionnaire is time-consuming, though they submitted valid questionnaires. Two other Finnish participants submitted unfinished questionnaires with comments that they had so many associates, and it was difficult to complete the questionnaires. These two questionnaires are regarded as invalid and were deleted from the sample. Similarly, five Chinese participants commented that it takes time to finish the questionnaire. However, no invalid questionnaire was found in the Chinese sample.

Regarding the chosen language of English, all the Finnish respondents were able to use English fluently both in writing and discussion, because they all have a high level of education and a position that requires English skills.

\section{Results}

Due to the research design, the maximum number of associates in a participant's network was limited to 25 . However, because an associate can be named in several networks, the actual number of associates in a participant's list is less than 25. The average network size is 9.0 and 14.8 individuals respectively for Chinese and Finnish participants. The characteristics of the associates are presented in Table 1. Although we excluded the occupation of the associates, as this is fragmented, it is interesting to note that in both countries, some of the married participants' husbands also hold a position in IT or related fields.

\section{[Insert Table 2 about here]}


Table 2 shows the characteristics of guanxi (network) bases regarding network contents. Family members were further categorized as male family members (father, brother) and female family members (mother, sister) so that we could investigate whether there was a gender effect related to network contents. The husband was excluded from family members so that the role of marriage in these women's networks could be identified. From the interview, we found that Chinese participants define a classmate as a member of a guanxi studying together with the participant at a school, college or training programme (similar to alumnus). This is why some of the classmates are younger than the Chinese interviewees. By contrast, only one Finnish participant mentioned a classmate in her 'socialize' network ${ }^{[1]}$. Family friends referred to the friends of the participant's family. Relatives are those who are connected with the participants by indirect blood or affinity ties. From the interview, we found that the Chinese participants' definition of a relative is different from that given above, in which brothers and sisters of the participants' fathers are considered family members. To some degree, this reflects the masculine (gendered) nature of traditional Chinese culture. In the Finnish cases, only two participants talked about their uncle and aunt as part of their 'socialize' networks; they otherwise did not list them as associates in the questionnaire.

It is interesting to note here the differing responses to 'who can be your friend?' For most Chinese participants, a friend can be one's co-worker or classmate, who is involved in all five types of network content. By contrast, most Finnish participants reported they would not make friends with their co-workers. They do not want to mix work and their personal life. Finnish participants most frequently list friends as associates within a 'socialize' network.

Associates' characteristics regarding network contents and demography are presented in Table 3 and Table 4 respectively. For Chinese participants: (1) male supervisors over 45 years old comprise the majority of the influence network, (2) associates over 45 years old are important for the participants regarding all five network contents, except for 'socialize', and (3) the majority of subordinates are younger than the participants and male. For Finnish participants: (1) males are the majority for advice and information, especially for the influence network, (2) the majority of co-workers are male, and (3) females are the majority in 'socialize'. The majority of the supervisors are more than 45 years old and male in both

\footnotetext{
${ }^{[1]}$ Maybe this is because Finland is a small country, the Finns like to use "colleague" more than "alumnus" if an associate belongs to both categories. Besides, the Finnish participants mention most "colleague” which refers to subordinate, colleague and supervisor. Usually, the interviewer has to ask the Finnish participants to specifically identify the position of the colleague compared with the interviewee during the interview. However, this is not the case concerning Chinese participants. Additionally, English is not the native language of the Finnish participants nor the interviewer (the first author), there might be some problems related to understanding and common interpretation of meaning.
} 
contexts, indicating a masculine and hierarchical managerial model even in a new industry like IT.

\section{[Insert Table 3 about here]}

\section{[Insert Table 4 about here]}

\section{Interpreting the Results Based on Comparisons}

\section{Women managers' gendered networks}

Gender is a part of socially constructed individual identity and has an effect on organizational relations between people (Acker, 1990). The data in Table 3 shows the effect of female-to-male dyads regarding power-related networks 'influence' for both Chinese and Finnish participants. There are several possible explanations for this. Research into early childhood socialization processes shows that females are better at acknowledging and understanding the feelings of others, while males tend to be more competitive and challenging (Gilligan, 1982; Tannen, 1994). So overall, women network easily with men in power-related networks. Further, this is because of the masculine nature of management, technology and hierarchy, in which managers are mostly men and subordinates take responsibility for their supervisors' routines, and in this way make contact and become networked with men. As the majority of Chinese participants reported, they always seek support from their male supervisors when they want to influence the outcome of an important decision at work. This might reflect a Chinese cultural tradition where authority and power belong to men.

In contrast, the Finnish participants had more male associates for 'advice' and 'information' compared to 'influence'. This may be explained by the fact that the organizational structure of Finnish IT companies is much less hierarchical than that of Chinese companies, or this may be because information and advice are more important for the Finnish participants than they are for their Chinese counterparts. Although managerial positions are dominated by males in Finland (Aaltio \& Heilmann, 2006; Kolbe, 2005), some Finnish participants have been recognized and pushed by their male co-workers into managerial careers:

"I have always had good male colleagues - they want to push me further to a more demanding job (becoming the CEO of the company).” (Finnish, 50, CEO)

"I have many old male friends, and they are very interested in my career. I have gotten to know them during these working years, and they're still, they want me to go up, go further [laugh]."(Finnish, 43, Director)

Meanwhile, the different extent of the tendency demonstrated by Chinese and Finnish female managers in their power- and work-related ties reflects the 
structural constraints that limit women's options of forming same-sex career success networks, especially when access to power and influence is the major motivation (cf. Bu \& Roy, 2005).

On examining the age variable, an asymmetrical effect between younger and older associates is revealed concerning the Chinese participants. Older associates are one of the majority guanxi bases and are most frequently involved in 'influence' and 'crisis' network content, while younger associates appear almost exclusively in 'advice' and 'socialize' content. Participants network more with older associates than with younger associates, especially for influence and crisis network content. Based upon the hierarchical nature of Chinese society in which the person higher up the hierarchy is the decision-maker and has more social capital (Chow \& Ng, 2004), it is argued that the choice of whether to network with a younger associate depends on the participant. However, it depends on the associate when it comes to networking with an older associate. This contact is not within the control of the participants. Even though this is the case, some participants reported that they still tried to network with their supervisors, who were usually older associates.

As the majority of Finnish associates were over 45 years old, it is not surprising that older associates are the most numerous in all types of Finnish participants' network content, but especially in 'influence' and 'crisis'. Generally, the older person is the decision-maker and has more social capital. This seems also true in the Finnish context.

\section{Size of Chinese and Finnish networks: small vs. large}

The results show Chinese networks are limited in size (average 9 individuals), which is smaller than that of their Finnish counterparts (average 14.8 individuals). The latter is almost the same as that of the participants in the study by Chow and Ng (2004), in which most of the participants are male managers. This may simply coincide with traditional Chinese culture, which emphasizes that the women's role is to be at home. Women's networking outside of the home is not encouraged within traditional Chinese culture. As we examine the data in more detail, we see that for both Chinese and Finnish participants, the average network size for any of the five network contents is almost the same, as presented in

Table 3. This indicates that Chinese participants always network with the same associate for different network content, while Finnish participants more often network with different associates for different network content, indicating some functional orientation for work and life networks.

According to structure hole theory (see Burt, 1992), Finnish participants have larger networks with non-redundant contacts and are rich in information benefits, while Chinese guanxi emphasizes strong ties, which are likely to be connected to redundant contacts. This cab be seen in the interview concerning 
"who could be your friend". Most Chinese participants said that it is quite normal that some of their co-workers also became friends. In contrast, only one Finnish participant said she had a friend who is also her colleague. As one Finnish participant stated: "I never make friends with my co-workers. Business is business, I do not want to mix them.”

Through the interviews, we found there are very few clubs especially for the Chinese participants. Joining a club and becoming a club member is not common for them. Although there are some professional associations for women managers and entrepreneurs, it seems they cannot meet the networking needs of these women managers. One Chinese participant commented: "In this association... it is still a quite hierarchical system.” So the need for women managers to network was not realized via participation in these associations.

The situation is different in Finland. Most of the Finnish participants reported that they are members of clubs and 'socialize' with the other members. For example, one Finnish participant is a member of a flying club, another is a member of the Rotary club, another a member of a horse riding club. One Finnish participant is a member of a network for women within her company. Finland is also well known for its egalitarian policies and social welfare system. Many projects have been launched nationally to encourage and support women's career development in the technology field; for example, 'WomEqual' and 'WomenIT ${ }^{\text {, }}{ }^{[1]}$. Joining a club or network enlarges one's social network, especially the informal network, which may become social capital in their managerial careers. This may also explain why Finnish participants have larger networks compared to their Chinese counterparts.

\section{Networking strategies: 'Who you know' vs. 'who knows you'}

In the Chinese context, the largest three guanxi bases are co-workers, classmates and family members respectively, while in the Finnish context, the largest three network bases are co-workers, friends and family members. As we can see in Table 2 and Table 4, the networks of women IT managers in both contexts are mainly work-related and male-dominated, although life-related networks are also important to them.

For the Chinese participants, supervisors are the most important guanxi base concerning career and work. Supervisors are those who control resources and power, and make decisions. As China is transforming from a planned economy to a market economy, the effect of traditional culture - especially its hierarchy and respect towards one's seniors is obvious even in a new industry like IT. This may

\footnotetext{
${ }^{[1]}$ WomEqual: http:/ /www.weme.fi/, aims to support women's career development, especially in technologyrelated fields, and implement a tool for women's networking. WomenIT - Women in Industry and Technology, is a development, training and research project, which aims to carry out the desegregation of the working life of gender identified traditional women's and men's jobs and tasks.
} 
explain why most of the associates for influence are male supervisors. Supervisors or those who make decisions are key associates in women's networking. When asked, "how you gain guanxi (networks)", one Chinese participant replied:

"In China we say 'who you know [guanxi]' is more important than 'what you know'. I try to develop long-term relationships with some potential people [with power]. Networking strategies are crucial. You need to show your loyalty, friendship and trust. It is always good to be nice to these people, as they may help you in the near future. It can be too late to start networking with an associate only when you need his help." (Chinese, 36, manager)

This implies that guanxi receivers may feel the burden to 'pay back', considering the reciprocal nature of guanxi (Chen \& Chen, 2004a).

Classmates are also a very important part of a guanxi base. As one participant said: "Classmates are important for me because by networking with my classmates, it is quite possible for me to get access to their networks". However, not all women adapt to male-dominated guanxi. "It is really hard for me to network with those male managers because I am not good at drinking and gambling [which are common hobbies among Chinese men]. Therefore, I need to work hard and do my best for performance”, one participant said. Most of the participants in our study emphasized the importance of on-the-job training and lifelong learning. This supports the research finding that women are more likely than men to try to learn more and to want to obtain more education as a career tactic (Granrose, 2007). From Table 2 we found that the participants shared more network content with non-family members than with family members. It is only in crisis situations and for advice that family members take on a prominent role. This is consistent with the Chinese idiom that 'blood is thicker than water', meaning that family members have a stronger obligation to help each other than other associates.

For the Finnish participants, colleagues and supervisors are the main associates for "influence”. Males dominated in all the work-related networks, including "influence", "information" and "advice”. This implies that the organizational culture in Finland is less hierarchical than that in China but is still male-dominated. Although supervisors make decisions in the organization, recommendations and information are crucial for the process of recruitment or appointment in Finnish companies.

"You need to have good friends in all directions, both downwards and upwards. ... because when they select a person for a higher position, it is all about who they know. They would not take anybody that they do not know into that position. So I think the network (is very important)." (Finnish, 35, manager)

This was one Finnish participant's answer to "what do you think is most important for women wanting to enter top managerial positions”. Being visible to senior and board level personnel, and adopting impression management techniques 
helps in being offered challenging work and high profile assignments (Morrison et al., 1987). Most of the Finnish participants indicate that they have used some impression management techniques to make their voice heard and show their performance to the decision-makers. To them, 'who knows you' is more important than 'what you know'.

However, women still face difficulty networking. As one participant said: "In this kind of (IT) industry, 80 per cent are men and they already have their networks. But there are so few women here, and one thing is that women do not dare encourage other women in their ambitions." This may explain why women mainly turn to male colleagues and supervisors for "influence”. Family members, especially husbands, parents and children, are still important for the Finnish participants. One participant stated, "I have a good, supportive husband with whom I can talk about both business and private issues”. Another participant emphasized her mother, who has her own company, as a role model for her career and life. Others talked about the happy times with their children.

\section{Implications for international human resource management}

Networking has been regarded as essential for guiding women to top managerial positions and career success (Kanter, 1977; Kaplan \& Niederman, 2006; Bu \& Roy, 2005). The gendered nature of networking for women managers and the different structures of their networks and networking strategies in the two cultural contexts in this study can be explained by the historical, cultural, social and legal systems of the two countries (cf. Bowen et al., 2007; Adya, 2008), which have implications for international human resource management. It is important for human resource management (HRM) decision-makers to know that on the one hand, women managers have less fully developed informal networks than men, which could affect their lack of advancement to high levels of management; on the other hand, women managers need to penetrate male networks to a greater extent to become sufficiently visible to win organizational promotions. In addition, networking for women managers is affected by national and organizational cultures, given the gendered nature of networking and networks (cf. Ibarra, 1993, 1997). To promote networking for women managers, companies are advised to launch cross-company and cross-gender networking programmes, which have characteristics that are likely to combat the advantages of men over women. Within this perspective, a cross-company, cross-gender approach seems to be ideal for women who are looking to move up (Schipani et al., 2008). This is because by joining various networks for various purposes, women gain diverse information and resources, such as emotional support and career progress.

As a result of identifying the differences in the composition of networks between Chinese and Finnish women managers and their networking strategies, foreign companies operating in China should focus their HRM decisions on organizational diversity and gender equality assessment, launching more cross- 
department and cross-company networking programmes to enlarge women managers' non-redundant networks and increase their visibility to colleagues and potential business partners. Foreign companies operating in Finland should concentrate their HRM decisions on the demographic characteristics of decisionmakers, except for focusing on organizational diversity and gender equality assessment. As a result of the male dominance in management positions, organizational practices are highly male dominated or even biased and are likely to form gender-based job segregation (Acker, 1990; Ibarra, 1993, 1997), which disadvantages women. Therefore, companies should build practices that are more robust and gender equitable. They should offer work experience programmes that discriminate in women's favour, and review their organizational cultures to try and make them less gender-biased, especially in corporate decision-making and job assignment. These approaches will attract more women to managerial careers.

\section{Reliability questions concerning the study}

This study is by nature qualitative and does not use statistical analysis. It combines several methods and kinds of data. It does not result in generalizations, but instead seeks to understand the phenomenon of networks and what it means for women managers in the cultures of China and Finland.

As the data description indicated, the (Finnish) interviewees were highly educated, presumably in engineering and/or business. It was stated that 12 interviewees out of the Finnish 15 had studied at university (at least) for a Masters degree, while only 7 Chinese interviewees (out of 21) and their associates had a similar level of education. In the Finnish education system this means that the Finnish interviewees had spent an average of 4-6 years at university, and it seems odd and even unlikely that the Finnish respondents would not have gained meaningful friends and business acquaintances at college or university. Yet, only one of the Finnish respondents listed "classmate" as part of her meaningful network.

The meaning of "classmate" to Chinese and Finnish respondents might differ. As stated at the article, Chinese respondents understood "classmate" to be someone they attended at college or university (p. 9) but the Finnish respondents probably understood it as luokkakaveri (in Finnish) which refers to highschool friends, while university and college friends would be kurssikaveri (in Finnish) or opiskelukaveri (in Finnish). However, schooling system in Finland is nowadays complex and the definitions are not absolutely stable. Classmate can, as well, be understood as a general description of a person from the times of study. However, the questions concerning language and meaning of words and concepts cannot be totally avoided in this kind of cross-cultural research and the issue of meanings is discussed throughout the paper because it focuses on comparison of Western concept of social capital and Chinese concept of guanxi. While this one detail might appear irrelevant, it however shows the challenge of cultural comparison. 
This research is exploratory due to the complex and interdependent nature of culture, gender and work. This research is qualitative and does not use a large sample or statistics about China and Finland. It adds to earlier Hofstede-like comparisons by being critical in terms of gender and sensitive to the cultural sites. The focus is on gender and the IT industry, but the results of this study can also be understood within a larger cultural framework and as a comparison of a northern European country and mainland China (Berry, 2005; Schaffer \& Riordan, 2005). Besides, the questionnaire may have restricted the participants from listing any other networks that may have been important to them. During the fieldwork, we received several comments from the participants on the questionnaire. For example, one Finnish participant said that the number of associates she had in "socialized" was much more than five. Another said it was difficult to recall every associate in each network context. One Finnish participant did not even finish the questionnaire because "it is time-consuming to fill it in" (the data from this participant was removed from the study). By contrast, almost no Chinese participants commented on the design of the questionnaire. Only one said it took her about one hour to finish the questionnaire. This may reflect different attitudes to participating in academic research in the two countries. One way or another, the Chinese participants took part in this study because of guanxi, and they would rather finish the questionnaire to help the interviewer. While the experience with the Finnish participants indicates their positive attitude to sharing knowledge. From this perspective, using a different methodology, such as a narrative approach, and also including male managers might reveal some other important features of networking among women.

\section{Conclusions and Further Research Questions}

Working within the IT industry was the context for all the Chinese and Finnish women managers in the study. As shown in a Finnish study, the IT sector is by nature open to networking, people have a lot of contacts outside their work and networking often uses horizontal business contacts (Aaltio \& Heilmann, 2006), compared for instance to the forest sector where people have long careers with the same employer. Knowledge and expertise changes fast in IT, and because the sector is still young, in general old networks do not exist like they do in other sectors. The study indicated that even though globalization is making work environments more similar than they used to be, professional progress for women and men in the company cultures of China and Finland still differ considerably. Women's experiences of networking and socializing could be described differently compared to men.

The study indicated that in both Chinese and Finnish contexts there is a significant effect of female-to-male dyads concerning power-related networks of 'influence', while female-to-female dyads are mostly related to 'socialize' networks. In addition, we find that: (1) Chinese networks are smaller than their 
Finnish counterparts, (2) Chinese participants are more likely to network with the same associate for several network contents, while Finnish participants have more non-redundant contacts because they intend to separate work and life related networks, and (3) male supervisors are the main associates for 'influence' for Chinese participants, while the main associates of 'influence' for the Finnish participants are both male colleagues and supervisors, which indicates a less hierarchical organizational culture in Finland. The results also show different networking strategies in each context.

Using social network analysis, this study explores the composition and structure of women's social networks, which are crucial to understanding women's careers. Our findings support earlier studies that indicate that inadequate social networks, especially informal ones, have been a barrier to career success for women (Kanter 1977; Kaplan \& Niederman, 2006; Powell, 2000), and confirm the traditional masculine image of the IT industry (Lindgren \& Packendorff, 2006). The limited size of Chinese networks indicates a more hierarchical organizational culture and the prevalence of redundant contacts in the Chinese context compared to their Finnish counterparts.

To overcome inadequate social networks, some strategies would benefit women in both contexts. These strategies include informal networking, visibility in organizations and impression management techniques. There are women-only networks, which seem successful for providing valuable emotional support; however, the majority of networking and mentoring programmes appear to broaden the gap between the sexes (Schipani et al., 2008). For a woman who truly has career advancement in mind, participation in a more mainstream network is highly advised. Accordingly, the best solution for women perhaps is to join in various networks for various purposes - including both emotional support and career progress. In addition, cross-company and cross-gender programmes have characteristics that are likely to combat the advantages of men over women. Given this perspective, a cross-company, cross-gender approach seems to be ideal for women who are looking to move up.

Career success for women today not only depends on 'what you know' but also 'who you know' and 'who knows you'. Both formal and informal networks may turn into useful social capital and trust, benefiting both individuals and organizations. We suggest that a women-friendly culture encourages more women to grow in a managerial career, which in turn might support career-oriented women to balance their gendered networks, and break organizational cultures that are male-dominated and resistant to change. According to Kumra and Vinnicompe (2010), impression management is a way to make oneself perceived and evaluated for career purposes, and is a daily tool that could be used in network promotion. Moreover, networking styles can be ad hoc, provisional, unstable, inconsequential or fortuitous. Gender sensitivity is also needed in this because dyads consisting either of men or women differ. Socializing that leads to a stable basis for 
communication and can be used for women managers' purposes, whether work or family related, is the core element for cumulative social capital or guanxi.

For Chinese and Finnish women this means different things. The Chinese culture is insider-orientated (Fang \& Faure, 2011) and Chinese have a clear propensity to engage in conversation with people they know and they have been introduced to and rarely speak to people they do not know. Trust is low in the case of people outside the family (Fukuyama, 1995). Building social capital means different things for women managers compared to men because they have to cross the insider border. So they bridge both the Chinese insider paradigm of communication, and the gender difference being “the other”. Because IT careers need outward contacts, the bridging is important. Finnish women managers are more used to bridging the gender and insider border because the culture is more outsider orientated and the Finnish are used to bridging the language border, using English in the global business environment.

Women in this study network most with female associates in order to 'socialize'. Future research might investigate the similarities and differences of male networks, female networks and mixed gender networks. The research might also examine the entry barriers to these networks, and report on the personal and career benefits these groups provide. For example, the Chinese women in this study report that playing cards, gambling and drinking wine is a must for joining male networks. Future research might also usefully investigate the networking of female managers who are members of influential networks. Since some women in this study report the benefits of having a mentor, further research might assess the advantages and disadvantages of same-gender and cross-gender mentoring. Finally, role models have also been mentioned by women in this study. Future research might also investigate the benefits that role models are seen to provide in the career development of female managers. In addition, expatriate women managers in China can act as a role model for local Chinese women managers, and vice versa.

Our study shows that there are connections between guanxi and European and American ideas of social capital. Chinese guanxi and Finnish approaches to networking look the same on the surface. Nevertheless, the traditions seem to differ and have an impact on the real nature of connecting and networking. On the one hand, national traditions affect organizational culture; on the other, organizational culture absorbs national traditions and makes old traditions less powerful (Berry, 2005; Fang \& Faure, 2011). Overall, research on networking must explore these features and the cultural background more deeply, considering traditions in order to understand the dynamics hidden in the social ties within networks.

What then is the criterion if we want to determine the success of networking, management careers or performance in general? In general, based on 
earlier knowledge, it was assumed that socializing and networks are a resource for women in their managerial careers. Making a career has both external and internal meaning. People may be happy if they can combine both private and public life issues, work and family. Moving up the organizational hierarchy is not everything that a career means for a woman. There are gendered ethical consequences of guanxi for Chinese women manager candidates, but also men's circles may exclude the networking potential of Finnish women managers (Aaltio \& Heilmann, 2006). For those women who seek career advancement in the economies of both China and Finland, understanding and using networking may be a powerful tool. Studying networking both in China and Finland still needs critical approaches in terms of the ethical consequences for women, as this study shows.

\section{References}

Aaltio, I., \& Heilmann, P. (2006). Information and Communication Technology sector characteristics in Finland - a challenge for women. In E. M. Trauth (Ed.), Encyclopedia of gender and information technology (pp. 780-785). Idea Group Reference.

Aaltio, I., \& Huang, J. H. (2007). Women managers' careers in information technology in China: High flyers with emotional costs. Journal of Organizational Change Management, 20(2), 227-244.

Aaltio, I., Kyrö P., \& Sundin E. (2008). Women entrepreneurship and social capital. A dialogue and construction. Copenhagen Business School Press.

Acker, J. (1990). Hierarchies, jobs, bodies: A theory of gendered organizations. Gender \& Society, 4(2), 139-158.

Adler, P. S., \& Kwon, S-W. (2002). Social capital: Prospects for a new concept. Academy of Management Review, 27(1), 17-40.

Adya, M. P. (2008). Women at work: Differences in IT career experiences and perceptions between South Asian and American women. Human Resource Management, 47(3), 601-635.

Ahuja, M. K. (2002). Women in the information technology profession: A literature review, synthesis and research agenda. European Journal of Information Systems, 11(1), 20-34.

Berry, J. W. (2005). Acculturation: Living successfully in two cultures. International Journal of Intercultural Relations, 29(6), 697-712.

Bian, Y. J. (1994). Work and inequality in urban China. Albany: State University of New York.

Björkman, I., \& Kock, S. (1995). Social relationships and business networks: The case of western companies in China. International Business Review, 4(4), 519-535. 
Bowen, C. C., Wu, Y., Hwang, C., \& Scherer, R. (2007). Holding up half of the sky? Attitudes toward women as managers in the People's Republic of China. International Journal of Human Resource Management, 18(2), 268-283.

Brannen, M. Y., \& Salk, J. (2000). Partnering across borders: Negotiating organizational culture in a German-Japanese joint venture. Human Relations, 53(4), 451-487.

Bu, N. L., \& Roy, J. P. (2005). Career success networks in China: Sex differences in network composition and social exchange practices. Asia Pacific Journal of Management, 22(4), 381-403.

Burke, R. J., \& Nelson, D. L. (2002). Advancing women's careers. Malden, MA: Blackwell.

Burke, R. J., Rothstein, M. G., \& Bristor, M. (1995). Interpersonal network of managerial and professional women and men: descriptive characteristics. Women in Management Review, 10(1), 21-27.

Burt, R. S. (1992). Structural holes: The social structure of competition. Cambridge, MA: Harvard University Press.

Burt, R. S. (1997). The contingent value of social capital. Administrative Science Quarterly, 42(2), 339-365.

Burt, R. S. (2001). Structural holes versus network closure as social capital. In N. Lin, K. Cook \& R. S. Burt (Eds), Social capital: Theory and research (pp. 31-56). New York: Aldine de Gruyter.

Calás, M. B., \& Smircich, L. (1992). Using the "F" word - Feminist theories and the social consequences of organizational research. In A. J. Mills \& P. Tancred (eds), Gendering organizational analysis (pp. 222-234). London: Sage.

Chen, C.C., Chen X.-P. \& Huang, S. (2013). Chinese Guanxi: An integrative review and directions for future research. Management and Organization review, 9(1), 167-207.

Chen, C. C., \& Chen, X. P. (2004a) Guanxi practices and trust in management: A procedural justice perspective. Organization Science, 15(2), 200-209.

Chen, C. C., \& Chen, X. P. (2009). Negative externalities of close guanxi within organizations. Asia Pacific Journal of Management, 26(1), 37-55.

Chen, X. P., \& Chen, C. C. (2004b). On the intricacies of the Chinese guanxi: A process model of guanxi development. Asia Pacific Journal of Management, 21(3), 305-324.

Chow, I., \& Ng, I. (2004). The characteristics of Chinese personal ties (guanxi): Evidence from Hong Kong. Organization Studies, 25(7), 1075-1093.

Coleman, J. S. (1988). Social capital in the creation of human capital. American Journal of Sociology, 94, Supplement, 95-120. 
Coleman, J. S. (1990). Foundations of social theory. Cambridge, MA: Harvard University Press.

Cooke, F. L. (2004). Women in management in China. In M.J. Davidson \& R. J. Burke (Eds), Women in management worldwide: Facts, figures and analysis (pp. 243-259). Ashgate: Corbnwall.

Creswell, J. W. (1998). Qualitative inquiry and research design: Choosing among five traditions. Thousand Oaks, CA: Sage.

Davidson, M., \& Burke, R. (2004). Women in management worldwide: Facts, figures and analysis. Ashgate, Cornwall.

Davies-Netzley, S. A. (1998). Women above the glass ceiling: Perceptions on corporate mobility and strategies for success. Gender and Society, 12(3), 339-355.

DelCampo, R. G., Jacobson, K. J. L., \& Van Buren III, H. J. (2011). Comparing immigrant and US born Hispanic business professionals: Insights and discrimination. Cross Cultural Management, 18(3), 327-350.

Dunfee, T. W., \& Warren, D. E. (2001). Is guanxi ethical? A normative analysis of doing business in China. Journal of Business Ethics, 32(3), 191-204.

Fang, T. (2012). Yin Yang: A new perspective on culture. Management and Organization Review, 8(1), 25-50.

Fang, T., \& Faure, G. O. (2011). Chinese communication characteristics: A Yin Yang perspective. International Journal of Intercultural Relations, 35(3), 320-333.

Faure, G. O., \& Fang, T. (2008). Changing Chinese values: Keeping up with paradoxes. International Business Review, 17(2), 194-207.

Gilligan, C. (1982). In a different voice: Psychological theory and women's development. Cambridge, MA: Harvard University Press.

Gold, T., Doug, G., \& Wank, D. (2002). Social connections in China. Institutions, culture and the changing nature of guanxi. Cambridge, MA: Cambridge University Press.

Granovetter, M. (1992). Problems of explanation in economic sociology. In N. Norhia and R. G. Eccles (Eds.), Networks and organizations: Structure, form, action (pp. 25-56). Boston, MA: Harvard Business School Press.

Granrose, C. S. (2007). Gender differences in career perceptions in the People's Republic of China. Career Development International, 12(1), 9-27.

Guntz, H., \& Heslin, P. (2005). Reconceptualizing career success. Journal of Organizational behaviour, 26(2), 105-111.

Fenstermaker, S., \& West, C. (eds.) (2002). Doing gender, doing difference: Inequality, power, and institutional change. New York: Routledge. 
Fukuyama, F. (1995). Trust: The social virtues and the creation of prosperity. London: Penguin.

Hatch, M. J. (1993). The dynamics of organizational culture. Academy of Management Review, 18(4), 657-693.

Hausmann, R., Tyson, L. D., \& Zahidi, S. (2008). The global gender gap report 2008. World Economic Forum.

Hofstede, G. (2001). Culture's consequence (second edition). Sage Publications.

Ibarra, H. (1993). Personal networks of women and minorities in management: A conceptual framework. Academy of Management Review, 18(1), 56-87.

Ibarra, H. (1997). Paving an alternative route: Gender differences in managerial networks. Social Psychology Quarterly, 60(1), 91-102.

Jacobs, J. B. (1979). A preliminary model of particularistic ties in Chinese Political Alliances: Kan-Ching and Kuan-his in a rural Taiwanese township. China Quarterly, 78, 237-273.

Kanter, R. M. (1977). Men and women of the corporation. New York: Basic Books.

Kaplan, D. M., \& Niederman, F. (2006). Career management concerns for women in IT. In E. M. Trauth (Ed.), Encyclopedia of gender and information technology (pp. 84-89). Idea Group Reference.

Kolbe, L. (2005). Portraying Finland: Facts and insights. Helsinki: Otava.

Kumra, S., \& Vinnicombe, S. (2010). Impressing for Success: A gendered analysis of a key social capital accumulation strategy. Gender, Work and Organization, 17(5), 521546.

Lankau, M. J., \& Scandura, T. A. (2002). An investigation of personal learning in mentoring relationships: Content, antecedents, and consequences. Academy of Management Journal, 45(4), 779-790.

Leana, C. R., \& Van Buren, H. J. (1999). Organizational social capital and employment practices. Academy of Management Review, 24(3), 538-555.

Lee, D. Y., \& Dawes, P. L. (2005). Guanxi, trust, and long-term orientation in Chinese business markets. Journal of International Marketing, 13(2), 28-56.

Leung, A. S. M. (2000). Gender differences in guanxi-behaviors: An examination of PRC state-owned enterprises. International Review of Women and Leadership, 6(10), 48-59.

Leung, K., Bhagat, R. S., Buchan, N. R., Erez, M., \& Gibson, C. B. (2005). Culture and international business: Recent advances and their implications for future research. Journal of International Business Studies, 36(4), 357-378. 
Leung, K., \& Bond, M. H. (1984). The impact of cultural collectivism on reward allocation. Journal of Personality and Social Psychology, 47(4), 793-804.

Lin, N. (2001). Social capital: A theory of social structure and action. Cambridge: Cambridge University Press.

Lindgren, M., \& Packendorff, J. (2006). What's new in new forms of organizing? On the construction of gender in project-based work. Journal of Management Studies, 43(4), 841866.

Luo, J. D. (2005). Particularistic trust and general trust: A network analysis in Chinese organizations. Management and Organization Review, 1(3), 437-458.

Luo, Y., Huang, Y., \& Lu, W. S. (2011). Guanxi and organizational performance: A metaanalysis. Management and Organizational Review, 8(1), 139-172.

Lyness, K. S., \& Thompson, D. E. (2000). Climbing the corporate ladder: Do female and male executives follow the same route? Journal of Applied Psychology, 85(1), 86-101.

Marsden, P. V. (1987). Core discussion networks of Americans. American Sociological Review, 52(1), 122-131.

Marshall, C., \& Rossman, G. B. (1999). Designing qualitative research (3rd ed.). Thousand Oaks, CA: Sage.

Morgan, G., \& Smircich, L. (1980). The case for qualitative research. Academy of Management Review, 5(4), 491-500.

Morrison, A. M., White, R. P., \& Velsor, E. Van. (1987). Breaking the glass ceiling. Reading, MA: Addison-Wesley.

Moulettes, A. (2007). The absence of women's voices in Hofstede's Cultural Consequences: A postcolonial reading. Women in Management Review, 22(6), 443 - 455.

Nahapiet, J., \& Ghoshal, S. (1998). Social capital, intellectual capital, and the organizational advantage. Academy of Management Review, 23(2), 242-266.

O’Leary, V. E., \& Ickovics, J. R. (1992). Cracking the glass ceiling: Overcoming isolation and alienation. In U. Sekeran, \& F. Leong (Eds), Womanpower: Managing in times of demographic turbulence (pp. 7-30). Beverly Hills, CA: Sage.

Ordonez de Pablos, P. (2005). Western and Eastern views on social networks. The Learning Organization, 12(5), 436-456.

Pan, Y., Rowney, J., \& Peterson, M. (2011). The structure of Chinese cultural traditions: An empirical study of business employees in China. Management and Organizational Review, 8(1), 77-95. 
Polsa, P. (2002). Power and distribution network structure in the People's Republic of China - The case of an inland city in transition. Helsinki: Swedish School of Economic and Business Administration.

Powell, G. N. (2000). The glass ceiling: Explaining the good and bad news. In M.J. Davidson, \& R. Burke (Eds), Women in management: Current research issues Vol. II (pp. 236-250). London: Sage.

Putnam, R. (1993). The prosperous community: Social capital and public life. The American Prospect, 4(13), 35-42.

Putnam, R. D. (1995). Bowling alone: America's declining social capital. Journal of Democracy, 6(1), 65-78.

Schaffer, B. S., \& Riordan, C. M. (2003). A review of cross-cultural methodologies for organizational research: A best-practices approach. Organizational Research Methods, 6(2), 169-215.

Schein, E. H. (1996). Culture: The missing concept in organization studies. Adminstrative Science Quarterly, 41(2), 229-240.

Schwartz, S. J., \& Unger, J. B. (2010). Biculturalism and context: What is biculturalism, and when is it adaptive? Commentary on Mistry and Wu. Human Development, 53(1), 2632.

Schipani, C., Dworkin, T. M., Kwolek-Folland, A., \& Maurer, V. G. (2008). Pathways for women to obtain positions of organizational leadership: The significance of mentoring and networking. Ross School of Business at University of Michigan working paper No. 1117. Retrieved July 20, 2012, from http://ssrn.com/abstract=1281466.

Shenkar, O., Luo, Y., \& Yeheskel, O. (2008). From 'distance' to 'friction': Substituting metaphors and redirecting intercultural research. Academy of Management Review, 33(4), 905-923.

Singleton, R. A., \& Straits, B. C. (1999). Approaches to social research. Oxford: Oxford University Press.

Takahashi, C., Yamagishi, T., Liu, J. H., Wang, F., Lin, Y., \& Yu, S. (2008). The intercultural trust paradigm: Studying joint cultural interaction and social exchange in real time over the Internet. International Journal of Intercultural Relations, 32(3), 215-228.

Tams, S., \& Arthur, M. B. (2007). Studying careers across cultures: Distinguishing international, cross-cultural, and globalization perspectives. Career Development International, 12(1), 86-98.

Tannen, D. (1994). Talking from 9 to 5: How women's and men's conversational styles affect who gets heard, who gets credit, and what gets done. New York: William Morrow. 
Tranth, E. M. (2002). Odd girl out: An individual differences perspective on women in the IT profession. Information Technology \& People, 15(2), 98-118.

Tsui, A. S. (1997). The HR challenge in China: The importance of guanxi. In D. Ulrich, M. Losey, \& G. Lake (Eds.), Tomorrow's HR management (pp. 337-344). New York: Wiley.

Tsui, A. S., \& Farh, J. L. (1997). Where guanxi matters: Relational demography and guanxi in the Chinese context. Work and Occupations, 24(1), 56-79.

Weisinger, J. Y., \& Trauth, E. M. (2003). The importance of situating culture in crosscultural IT management. IEEE Transactions in Engineering Management, 50(1), 26-30.

Weiss, R. S. (1994). Learning from strangers: The art and method of quantitative interviewing. New York: The Free Press.

Wellman, B. (2001). Physical place and cyberplace: The rise of personalized networking. International Journal of Urban and Regional Research, 25(2), 227-252.

Whiting, V., \& de Janasz, S. (2004). Mentoring in the 21st century: Using the Internet to build skills and networks. Journal of Management Education, 29(3), 275-293.

Xiao, Z. X., \& Tsui, A. S. (2007). Where brokers may not work: The culture contingency of social capital in Chinese high-tech firms. Administrative Science Quarterly, 52(1), 1-31.

Yang, M. M. (1994). Gifts, favors and banquets: The art of social relationships in China. New York: Cornell University Press. 
Table 1.

Characteristics of the participants and their associates

\begin{tabular}{|c|c|c|c|c|c|}
\hline & \multicolumn{2}{|c|}{ Participants (\%) } & \multicolumn{2}{|c|}{ Associates (\%) } \\
\hline & & $\overline{C N^{1}(n=21)}$ & $F I^{2}(n=15)$ & CN $(n=190)$ & FI $(n=222)$ \\
\hline \multicolumn{2}{|c|}{ Female } & 100 & 100 & 46.4 & 38.6 \\
\hline & $\leq 30$ & 23.8 & & 21.6 & 4.8 \\
\hline \multirow{4}{*}{ Age } & $31-35$ & 28.6 & 6.7 & 23.2 & 10.3 \\
\hline & $36-40$ & 33.3 & 26.7 & 22.1 & 23.5 \\
\hline & $41-45$ & 14.3 & 26.7 & 10.0 & 22.1 \\
\hline & $45+$ & & 40.0 & 23.2 & 39.3 \\
\hline \multicolumn{2}{|c|}{ Married } & 52.4 & 66.7 & 72.1 & 69.1 \\
\hline \multicolumn{2}{|c|}{ University degree } & 90.5 & 100 & 69.5 & 92.3 \\
\hline \multicolumn{2}{|c|}{ (Master and above) } & (33.4) & $(80)$ & $(24.2)$ & $(66.2)$ \\
\hline
\end{tabular}

${ }^{1} \mathrm{CN}=$ Chinese; ${ }^{2} \mathrm{FI}=$ Finnish 
Table 2.

Characteristics of guanxi bases regarding network contents: results of $x^{2}$ test $n(\%)$

\begin{tabular}{|c|c|c|c|c|c|c|c|}
\hline $\begin{array}{l}\text { Guanxi or } \\
\text { network bases }\end{array}$ & & Advice & Infor. $^{3}$ & Influ. $^{4}$ & Crisis & Socialize & $x^{2}$ \\
\hline \multirow{2}{*}{ Classmates } & $\mathrm{CN}^{1}$ & $20(23.8)$ & $11(16.2)$ & $10(13.5)$ & $14(17.7)$ & $27(34.6)$ & $12.27 *$ \\
\hline & $\mathrm{FI}^{2}$ & - & - & - & $\longrightarrow$ & $1(1.7)$ & - \\
\hline \multirow{2}{*}{ Supervisors } & $\mathrm{CN}$ & $9(10.7)$ & $17(25.0)$ & $24(32.4)$ & $6(7.6)$ & $8(10.3)$ & $17.72^{* *}$ \\
\hline & FI & $13(22.8)$ & 11(19.6) & $20(41.7)$ & $14(24.6)$ & - & 3.10 \\
\hline \multirow{2}{*}{ Colleagues } & $\mathrm{CN}$ & $9(10.7)$ & 14(20.6) & 13(17.6) & $6(7.6)$ & $7(9.0)$ & 5.18 \\
\hline & FI & 16(28.1) & 31(55.4) & $21(43.8)$ & 11(19.3) & $1(1.7)$ & $31.25^{* *}$ \\
\hline \multirow{2}{*}{ Subordinates } & $\mathrm{CN}$ & $2(2.4)$ & $5(7.4)$ & $2(2.7)$ & $1(1.3)$ & $1(1.3)$ & 4.91 \\
\hline & FI & 11(19.3) & $14(25)$ & $7(14.5)$ & $3(5.2)$ & - & $7.857^{*}$ \\
\hline \multirow{2}{*}{$\begin{array}{l}\text { Male family } \\
\text { members }\end{array}$} & $\mathrm{CN}$ & $7(8.3)$ & $6(8.8)$ & $5(6.8)$ & $13(16.5)$ & $6(7.7)$ & 5.57 \\
\hline & FI & $4(7)$ & - & - & $4(7.0)$ & $4(6.6)$ & 0.00 \\
\hline \multirow{2}{*}{$\begin{array}{l}\text { Female family } \\
\text { members }\end{array}$} & $\mathrm{CN}$ & 10(11.9) & $2(2.9)$ & $3(4.1)$ & $14(17.7)$ & $4(5.1)$ & $16.24^{* *}$ \\
\hline & FI & $2(3.5)$ & $\longrightarrow$ & - & $8(14.0)$ & $9(14.8)$ & 4.526 \\
\hline \multirow{2}{*}{ Husbands } & $\mathrm{CN}$ & 11(13.1) & $3(4.4)$ & $5(6.8)$ & 11(13.9) & $5(6.4)$ & 8.00 \\
\hline & FI & $6(10.5)$ & - & - & $7(12.3)$ & $2(3.4)$ & 2.80 \\
\hline \multirow{2}{*}{ Friends } & $\mathrm{CN}$ & $9(10.7)$ & $4(5.9)$ & $7(9.5)$ & $9(11.4)$ & $16(20.5)$ & 8.667 \\
\hline & FI & $5(8.8)$ & - & - & $10(17,5)$ & $44(72.0)$ & $42.42 * *$ \\
\hline \multirow{2}{*}{ Family friends } & $\mathrm{CN}$ & $4(4.8)$ & $3(4.4)$ & $2(2.7)$ & $3(3.8)$ & $2(2.6)$ & 1.00 \\
\hline & FI & - & $\longrightarrow$ & - & $\longrightarrow$ & $\longrightarrow$ & $\longrightarrow$ \\
\hline \multirow{2}{*}{ Relatives } & $\mathrm{CN}$ & $3(3.6)$ & $3(4.4)$ & $3(4.1)$ & $2(2.5)$ & $2(2.6)$ & 0.46 \\
\hline & FI & - & $\longrightarrow$ & - & - & - & $\longrightarrow$ \\
\hline
\end{tabular}


Table 3.

Characteristics of the associates regarding network contents: descriptive statistics n(\%)

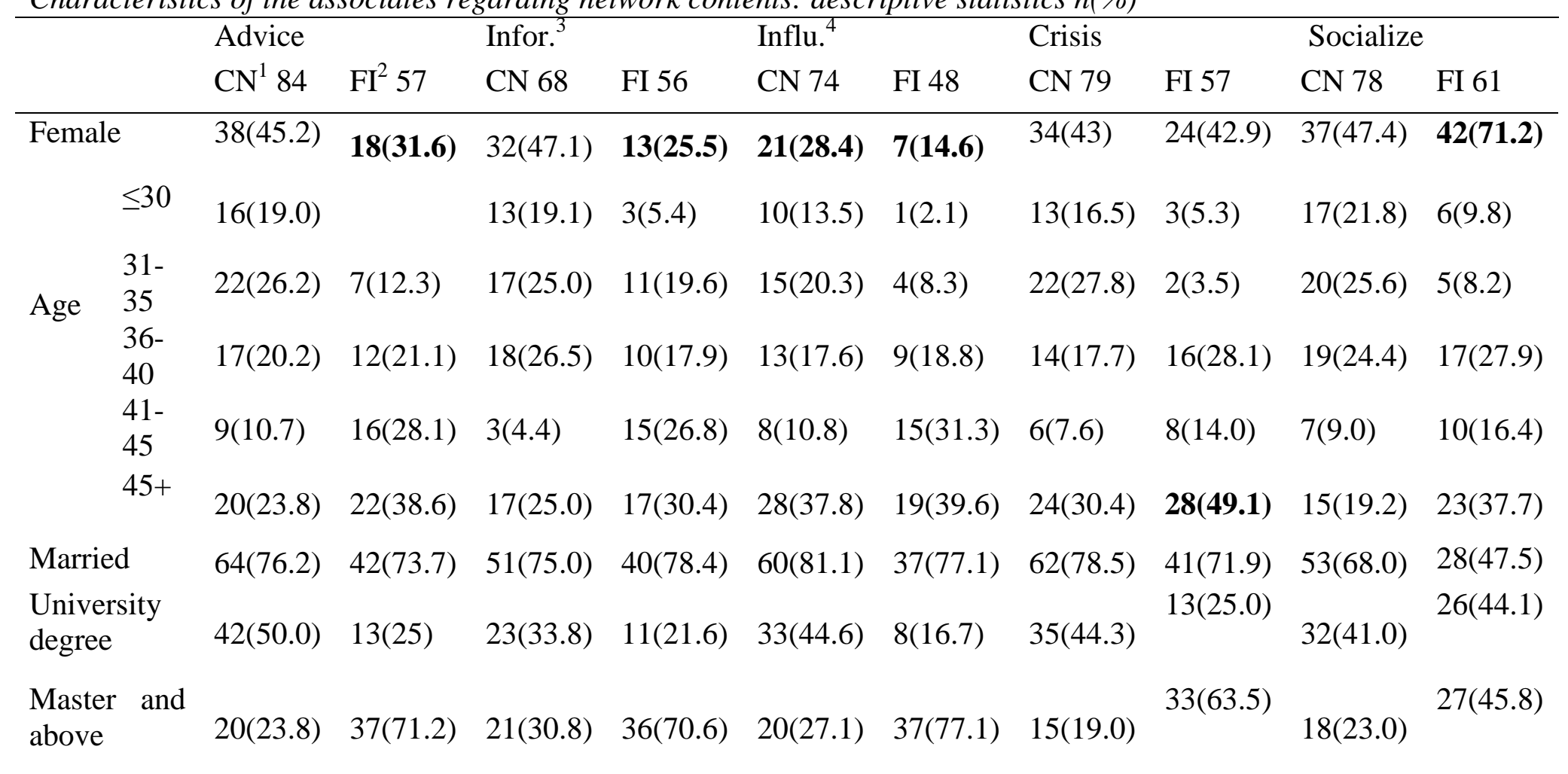

${ }^{1} \mathrm{CN}=$ Chinese; ${ }^{2} \mathrm{FI}=$ Finnish; ${ }^{3}$ Infor. $=$ Information; ${ }^{4}$ Influ.=Influence 
Table 4.

Characteristics of Guanxi bases regarding relational demography: descriptive statistics n(\%)

\begin{tabular}{|c|c|c|c|c|c|c|c|c|c|c|c|}
\hline \multicolumn{7}{|c|}{ Guanxi or networkAge } & \multirow{2}{*}{$\begin{array}{l}\text { Sex } \\
\text { Female }\end{array}$} & \multicolumn{2}{|c|}{ Education } & \multicolumn{2}{|c|}{ Marriage status } \\
\hline bases & & $\leq 30$ & $31-35$ & $36-40$ & $41-45$ & $45+$ & & Bachelor & MD \& PhD & Single & Married \\
\hline \multirow[t]{2}{*}{ Classmates } & $\mathrm{CN}^{1}$ & 26(52) & $7(14)$ & $11(22)$ & $5(10)$ & $1(2)$ & $29(58)$ & $32(64)$ & $11(22)$ & $27(54)$ & $23(46)$ \\
\hline & $\mathrm{FI}^{2}$ & 0 & 0 & 0 & 0 & $\mathbf{0}$ & $\mathbf{0}$ & 0 & 0 & 0 & 0 \\
\hline \multirow[t]{2}{*}{ Supervisors } & $\mathrm{CN}$ & $1(3.6)$ & $5(17.9)$ & $7(25)$ & $1(3.6)$ & 14(50) & $6(21.4)$ & $12(42.9)$ & $10(36.7)$ & $3(10.7)$ & $25(89.3)$ \\
\hline & FI & $\mathbf{0}$ & 0 & $10(16.9)$ & $16(27.1)$ & $33(55.9)$ & $7(11.9)$ & $11(18.6)$ & $46(78.0)$ & $11(18.6)$ & $48(81.4)$ \\
\hline \multirow[t]{2}{*}{ Colleagues } & $\mathrm{CN}$ & $3(11.5)$ & $9(34.6)$ & $10(38.5)$ & $3(11.5)$ & $1(3.8)$ & $17(65.4)$ & 19(73.1) & $7(26.9)$ & $3(11.5)$ & $23(88.5)$ \\
\hline & FI & $4(4.9)$ & $18(22.0)$ & $17(20.7)$ & $18(22.0)$ & $25(30.5)$ & $24(29.3)$ & $11(13.4)$ & $67(81.7)$ & $23(28.0)$ & $59(72.0)$ \\
\hline \multirow{4}{*}{$\begin{array}{l}\text { Subor- } \\
\text { dinates } \\
\text { MFM }^{3}\end{array}$} & $\mathrm{CN}$ & $5(45.5)$ & $2(18.2)$ & $3(27.3)$ & $1(9.1)$ & 0 & $3(27.3)$ & $7(63.6)$ & $3(27.3)$ & $5(45.5)$ & $6(54.5)$ \\
\hline & FI & $2(7.1)$ & $6(21.4)$ & $5(17.9)$ & $7(25.0)$ & $8(28.6)$ & $10(35.7)$ & $8(28.6)$ & $19(67.9)$ & $6(21.4)$ & $22(78.6)$ \\
\hline & $\mathrm{CN}$ & 0 & 0 & $1(7.1)$ & $2(14.3)$ & 11(78.6) & 0 & $3(21.4)$ & 0 & 0 & $14(100)$ \\
\hline & FI & $2(16.7)$ & & $1(8.3)$ & $1(8.3)$ & $8(66.7)$ & 0 & $7(58.3)$ & $5(41.7)$ & $4(33.3)$ & $8(66.7)$ \\
\hline \multirow[t]{2}{*}{$\mathrm{FFM}^{4}$} & $\mathrm{CN}$ & 0 & $3(17.6)$ & $3(17.6)$ & $1(5.9)$ & $10(58.8)$ & $17(100)$ & $5(29.4)$ & 0 & $1(5.9)$ & $16(94.1)$ \\
\hline & FI & $\overline{4(20.0)}$ & & $4(20.0)$ & $4(20.0)$ & $8(40.0)$ & $20(100)$ & $8(40.0)$ & $9(45.0)$ & $8(40.0)$ & $12(60.0)$ \\
\hline \multirow[t]{2}{*}{ Husband } & $\mathrm{CN}$ & $2(18.2)$ & $4(36.4)$ & $2(18.2)$ & $3(27.3)$ & 0 & 0 & 6(54.5) & $4(36.4)$ & 0 & 11(100) \\
\hline & FI & & & $7(46.7)$ & $3(20.0)$ & $5(33.3)$ & 0 & $3(20.0)$ & $9(60.0)$ & 0 & $15(100)$ \\
\hline \multirow[t]{2}{*}{ Friend } & $\mathrm{CN}$ & $2(9.1)$ & $10(45.5)$ & $2(9.1)$ & $2(9.1)$ & $6(27.3)$ & $14(63.6)$ & $7(31.8)$ & $8(36.4)$ & $12(54.5)$ & $10(45.5)$ \\
\hline & FI & $1(1.8)$ & $4(7.3)$ & $20(36.4)$ & $11(20.0)$ & $19(34.5)$ & $43(78.2)$ & $23(41.8)$ & $25(45.5)$ & $32(58.2)$ & $23(41.8)$ \\
\hline \multirow{4}{*}{$\begin{array}{l}\text { Family } \\
\text { friend } \\
\text { Relative }\end{array}$} & $\mathrm{CN}$ & 0 & $2(33.3)$ & $2(33.3)$ & $1(16.7)$ & $1(16.7)$ & $4(66.7)$ & 0 & 0 & 0 & $6(100)$ \\
\hline & FI & $\overline{0}$ & 0 & 0 & 0 & 0 & 0 & 0 & 0 & 0 & 0 \\
\hline & $\mathrm{CN}$ & $2(40.0)$ & $2(40.0)$ & $1(20.0)$ & 0 & 0 & $1(20.0)$ & $4(80.0)$ & $1(20.0)$ & $2(40.0)$ & $3(60.0)$ \\
\hline & FI & 0 & 0 & 0 & 0 & 0 & 0 & 0 & 0 & 0 & 0 \\
\hline
\end{tabular}

${ }^{1} \mathrm{CN}=$ Chinese; ${ }^{2} \mathrm{FI}=$ Finnish; ${ }^{3}$ MFM=Male family member; ${ }^{4} \mathrm{FFM}=$ Female family member 